\title{
Giant reversible barocaloric effects in Nitrile Butadiene Rubber around room temperature
}

\author{
E. O. Usuda ${ }^{1,2}$, W. Imamura ${ }^{1,3}$, N. M. Bom ${ }^{1}$, L. S. Paixão ${ }^{1}$ and A. M. G. Carvalho ${ }^{1}$ \\ ${ }^{1}$ Laboratório Nacional de Luz Síncrotron (LNLS), Centro Nacional de Pesquisa em Energia e Materiais \\ (CNPEM),CEP 13083-100, Campinas, SP, Brazil \\ ${ }^{2}$ Departamento de Ciências Exatas e da Terra, Universidade Federal de São Paulo (UNIFESP), CEP 00972 - \\ 270, Diadema, SP, Brazil. \\ ${ }^{3}$ Faculdade de Engenharia Mecânica, Universidade Estadual de Campinas (UNICAMP), CEP 13083-860, \\ Campinas, SP, Brazil.
}

\begin{abstract}
Elastomers have shown to be promising barocaloric materials, being suitable candidates for solid-state cooling devices. Moreover, this family of polymers presents additional advantages, such as their low cost and long fatigue life. In this context, we investigated the barocaloric effects in Nitrile Butadiene Rubber (NBR) in a large range around room temperature. Moderated applied pressures on NBR yield giant temperature change $\left(\Delta \mathrm{T}_{\mathrm{S}}\right)$ and entropy change $\left(\Delta \mathrm{S}_{\mathrm{T}}\right)$, reaching the maximum values of $16.4(2) \mathrm{K}$ at $323 \mathrm{~K}$ and $59(6) \mathrm{J} \mathrm{kg}^{-1} \mathrm{~K}^{-1}$ at 314 $\mathrm{K}$, respectively, for a pressure change of $390 \mathrm{MPa}$. Besides, both $\Delta \mathrm{T}_{\mathrm{S}}$ and $\Delta \mathrm{S}_{\mathrm{T}}$ have shown to be rather reversible. An influence of the glass transition on the barocaloric effects was verified: the glassy state tends to diminish the entropy and temperature changes in comparison with the rubbery state. Furthermore, we calculated the pressure coefficient of glass transition $\left(\mathrm{dT}_{\mathrm{g}} / \mathrm{dP}\right)$ obtained from different processes. Our study evidences the potential of NBR for cooling applications based on barocaloric effect, but also points out the glass transition must be avoided for a better barocaloric performance.
\end{abstract}

\section{INTRODUCTION}

The Nitrile Butadiene Rubber (NBR) is a well-known polymer from the family of elastomers with remarkable mechanical and chemical properties. NBR is an unsaturated copolymer formed by chains composed of butadiene $\left(\mathrm{C}_{4} \mathrm{H}_{6}\right)$ and acrylonitrile $\left(\mathrm{C}_{3} \mathrm{H}_{3} \mathrm{~N}\right)$. The rubber-like behavior (elasticity), the resistance to chemical agents (e.g. oils and acids) and low-cost make the NBR an interesting material for applications in many fields, such as automotive and aeronautic industry, as well as for making disposable equipment [1]. In recent years, elastomers have been found to be promising materials for applications in solid-state cooling [2-5]. Despite the favorable properties of NBR, this elastomer has not been explored in view of its cooling potential to date.

Current refrigeration technology is based in vapor-compression cycles, which brings environmental and energetic issues. Aiming to solve these problems, solid-state cooling devices appear as promising options [6-8]. This technology is based in materials which present $i$-caloric effects, in other words, materials exhibiting a thermal response when exposed to an external field change ( $i$ stands for intensive thermodynamic variables denoting the external fields). The nature of the external field can be magnetic $(H)$, electric $(E)$ or mechanical $(\sigma)$. Therefore, we can categorize the $i$-caloric effects as: magnetocaloric $(h-$ 
$\mathrm{CE})$, electrocaloric ( $e$-CE) and mechanocaloric effects $(\sigma-\mathrm{CE})$. The later can be subdivided in barocaloric $\left(\sigma_{b}\right.$-CE) and elastocaloric effect $\left(\sigma_{e}-\mathrm{CE}\right)$. Over the past two decades, the research on caloric materials have seen a fast growth due to the discoveries of the giant $h$-CE in $\mathrm{Gd}_{5} \mathrm{Si}_{2} \mathrm{Ge}_{2}$ compound in 1997 [9], the giant $e-\mathrm{CE}$ in $\mathrm{PbZr}_{0.95} \mathrm{Ti}_{0.05} \mathrm{O}_{3}$ in 2006 [10] and the giant $\sigma_{b}$-CE in Ni-Mn-In shape-memory alloy in 2010 [11]. However, the studies on $i$-caloric materials date from 1805, when J. Gough reported a temperature change in natural rubber under rapid stretching $\left(\sigma_{e}\right.$-CE) [12]. Decades later, W. Thomson predicted the $\sigma$-CE, $h$-CE and $e$-CE using thermodynamic considerations $[13,14]$.

Regarding the $\sigma_{b}$-CE, it is the least studied $i$-caloric effect so far. Only a small number of materials with giant $\sigma_{b}$-CE have been reported in the literature, such as: some shapememory alloys (SMA) [11,15], fluorites [16-20], magnetic materials [21-23], ferri/ferroelectric materials [24,25] and a hybrid perovskite [26]. Polymers also exhibit potential as great $\sigma_{b}$-CE materials. In 1982, a giant $\sigma_{b}$-CE was measured in poly(methyl methacrylate) [27]. More recently, interesting results were reported for elastomers: vulcanized natural rubber (V-NR) [3] and polydimethylsiloxane (PDMS) [4] showed giant $\sigma_{b}$-CE around room temperature. Furthermore, supergiant $\sigma_{b}$-CE was measured in acetoxy silicone rubber [5]. One advantage of elastomers is that they exhibit giant $\sigma_{b}$-CE around room temperature even in absence of phase transitions. This yields to very high and wide table-like $\sigma_{b}$-CE [2-4].

In this context, NBR appears as a new option of barocaloric material for application. Here, we investigate the $\sigma_{b}$-CE in NBR in a large range around room temperature at moderate pressures (up to $390 \mathrm{MPa}$ ). Direct measurements of temperature change $\left(\Delta \mathrm{T}_{\mathrm{S}}\right)$ yielded giant values. Strain $(\varepsilon)$ versus temperature $(T)$ data allowed us to calculate the isothermal entropy change $\left(\Delta \mathrm{S}_{\mathrm{T}}\right)$. Moreover, we observed both $\Delta \mathrm{T}_{\mathrm{S}}$ and $\Delta \mathrm{S}_{\mathrm{T}}$ results are clearly hindered by the glass transition, which shifts to higher temperature with the applied pressure.

\section{EXPERIMENT}

We used a commercial vulcanized NBR sample reinforced with carbon black fillers provided by Elastim company. The material was supplied in a long cylindrical shape with a diameter of $12 \mathrm{~mm}$. The sample with $8 \mathrm{~mm}$ in diameter and $20 \mathrm{~mm}$ in length was formed from the supplied material. The density of the sample, measured with a pycnometer, is 1390(10) $\mathrm{kg} \mathrm{m}^{-3}$. We characterized the NBR sample via Fourier transform infrared spectroscopy (see Fig. 1 in the Supplemental Material [28]) using a PerkinElmer spectrometer (model spectrum Two).

The experimental setup and procedures used in the present work are described in detail elsewhere [2-4,29]. Strain vs. temperature experiments were performed through isobaric processes, i.e., the temperature was varied, in a rate of $4 \mathrm{~K} / \mathrm{min}$, between $213-333 \mathrm{~K}$ under constant pressures within the $4-390 \mathrm{MPa}$ range.

Direct $\Delta \mathrm{T}_{\mathrm{S}}$ measurements were performed by applying/releasing pressure (maximum values within the range of $26-390 \mathrm{MPa}$ ) in a quasi-adiabatic condition. When the temperature in the sample is stable at the set point, a compressive stress is rapidly applied, resulting in a sharp increase in temperature. The load is kept constant until the temperature downs to the initial value. Finally, the stress is fastly released, causing an abrupt decrease in the sample's temperature. 


\section{RESULTS AND DISCUSSION}

$\Delta \mathrm{T}_{\mathrm{S}}$ data as a function of the initial temperature for compression and decompression processes are shown in Fig. 1(a). Both processes present very close results in the compared temperature range $(293-324 \mathrm{~K})$. At $390 \mathrm{MPa}$, we observe a maximum $\Delta \mathrm{T}_{\mathrm{S}}$ value of $16.4(2)$ $\mathrm{K}$ (at $323 \mathrm{~K}$ ) for decompression. This giant barocaloric $\Delta \mathrm{T}_{\mathrm{S}}$ surpasses or it is comparable to the best barocaloric intermetallics reported so far [30]. Normalizing this result by the applied pressure $\left(\left|\Delta \mathrm{T}_{\mathrm{S}} / \Delta \sigma\right|\right)$ we have a huge value of $42(2) \mathrm{K} \mathrm{GPa}^{-1}$. For the two lowest pressures, the $\Delta \mathrm{T}_{\mathrm{S}}$ curves present a slight ascending behavior as the temperatures increases. On the other hand, for $86 \mathrm{MPa}$ and above, we observe a stronger dependence of the $\Delta \mathrm{T}_{\mathrm{S}}$ with temperature: the curves show a smooth increase of the $\Delta \mathrm{T}_{\mathrm{S}}$ values, tending to saturate at higher temperatures (plateau). This behavior can be attributed to the influence of the glass transition of the NBR, since the mobility of the chains is significantly reduced as the material changes from the rubbery state (plateau) to the glassy state (steep region and below). Therefore, $\Delta T_{S}$ values tend to decrease below the glass transition temperature $\left(\mathrm{T}_{\mathrm{g}}\right)$. Corroborating this hypothesis, a similar behavior was reported by Bom et al in vulcanized natural rubber [3].
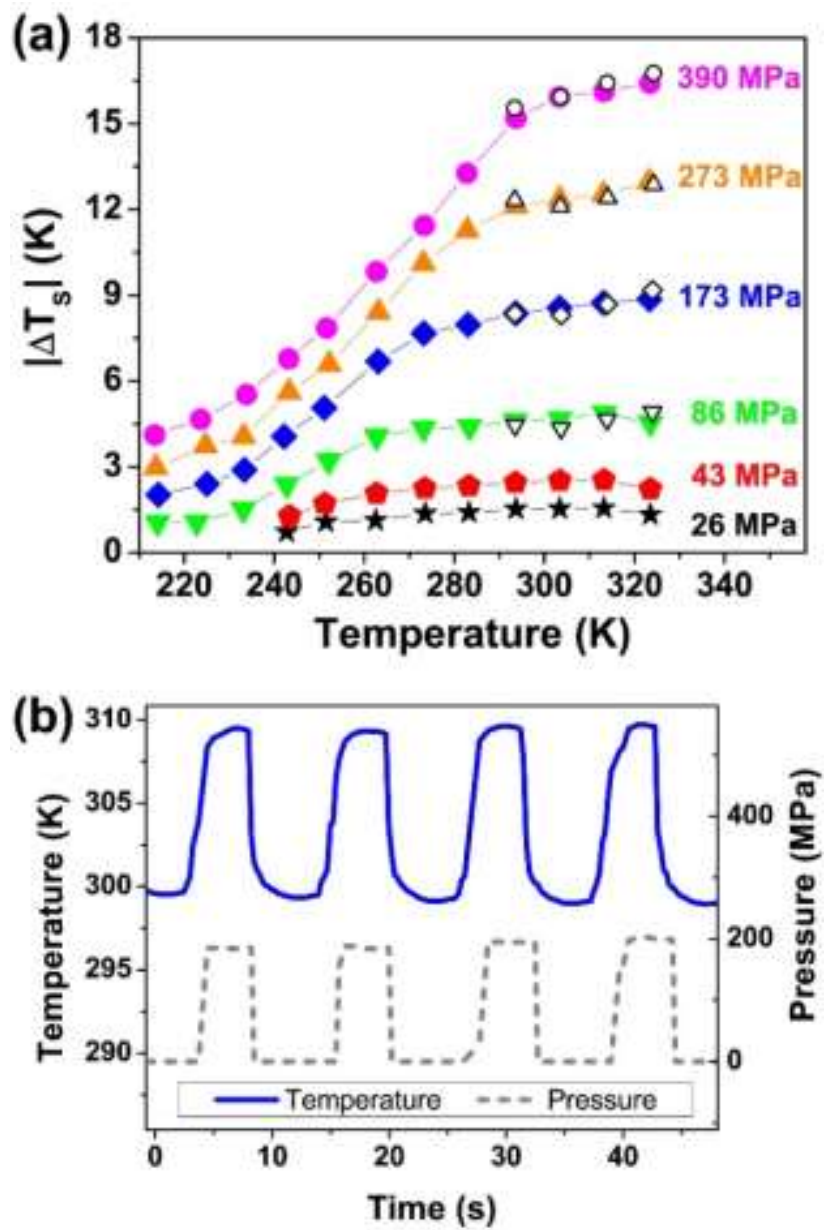

FIG. 1. (a) Adiabatic temperature change $\left(\Delta \mathrm{T}_{\mathrm{S}}\right)$ vs initial temperature. Solid symbols represent the measurements for the decompression processes, while the open symbols represent the compression processes. The NBR sample was measured at different pressure variations: 26.0(5), 43(1), 86(2),

173(3), 273(8) and 390(12) MPa. The line connecting the dots are guides for the eyes. (b) Temperature (blue curve) and pressure (grey curve) vs time for four compression-decompression cycles, after several similar cycles. 
In Fig. 1(b), the temperature and pressure are shown as a function of time for sequential adiabatic compression-decompression cycles. Note that the procedure is different from the measurements of $\Delta \mathrm{T}_{\mathrm{S}}$. Here, the sample does not return to the initial temperature after the pressure is applied. The behavior of the temperature change shows a rather reversible process, since the temperature change in compression is very close to the temperature change in decompression, with a difference less than $3 \%$. Furthermore, the magnitude of the temperature change $(\sim 10 \mathrm{~K})$ remains the same for repeated applications of pressure, also showing the reproducibility of these cycles.

It is a known fact that $T_{g}$ is sensitive to pressure [3,30-35], so it is expected that $T_{g}$ shifts to higher values as pressure increases. This behavior is shown in Fig. 2, where $T_{\mathrm{g}}$ was calculated from $\Delta \mathrm{T}_{\mathrm{S}}$ and $\varepsilon$ vs $\mathrm{T}$. data for pressures within the range of $0-390 \mathrm{MPa}$. We defined $\mathrm{T}_{\mathrm{g}}$ as the point where the third derivative is zero in the curves of Fig. 1 and StrainTemperature data (See Fig. 2 and Fig. 3 in Supplemental Material [28]). Values from strain data exhibit distinct slopes for cooling and heating processes. This discrepancy occurs due to the different kinects involving glass transformation on cooling and heating processes, which may shift the $\mathrm{T}_{\mathrm{g}}$ to higher or lower values [34,37]. In the cooling process, $\mathrm{T}_{\mathrm{g}}$ values are lower than those in the heating process, which is expected for polymers, since the material is coming from an equilibrium state (above $\mathrm{T}_{\mathrm{g}}$ ) to a non-equilibrium one (below $\mathrm{T}_{\mathrm{g}}$ ).

For $\mathrm{T}_{\mathrm{g}}$ obtained from $\Delta \mathrm{T}_{\mathrm{S}}$ data, we observe the curve is in between the cooling and heating curves. This is possibly explained by the differences in the processes [38]. On one hand, the $\varepsilon$ vs. T was performed at isobaric process. On the other hand, $\Delta \mathrm{T}_{\mathrm{S}}$ is measured when pressure is applied very quickly increasing the sample's temperature; then, the material cools down to the initial temperature and the pressure is released. These two distinct experimental procedures may yield different results. Still, there is a good agreement between the data from both methods considering the estimated errors. The pressure coefficient of the glass transition temperature $\left(\mathrm{dT}_{\mathrm{g}} / \mathrm{dP}\right)$ for the heating, cooling and $\Delta \mathrm{T}_{\mathrm{S}}$ curves are $0.186(4), 0.14(2)$ and 0.11(4) $\mathrm{K} \mathrm{MPa}^{-1}$, respectively.

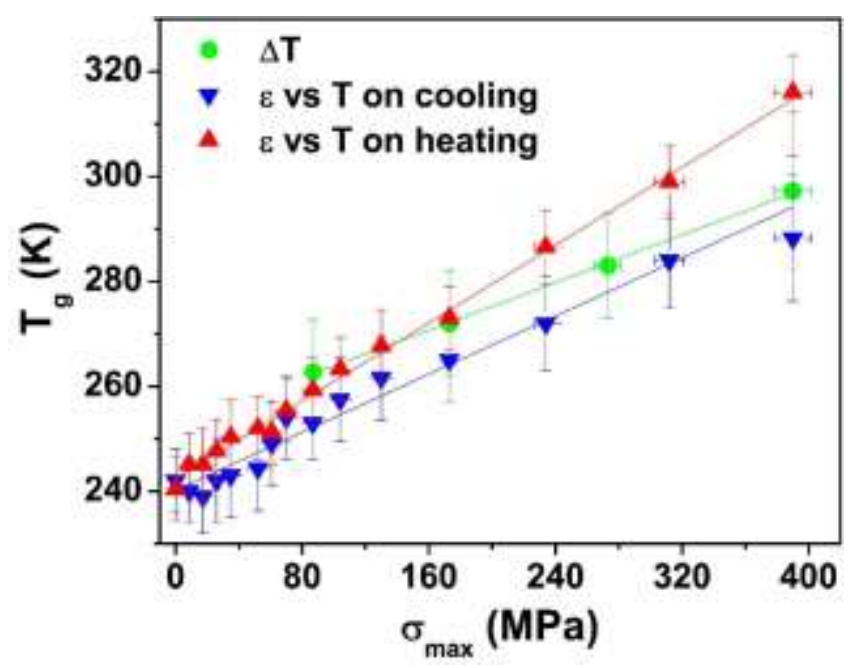

FIG. 2. Glass transition temperature $\left(\mathrm{T}_{\mathrm{g}}\right)$ vs pressure $(\sigma)$ for NBR. Up triangles and down triangles correspond to $\mathrm{T}_{\mathrm{g}}$ calculated from $\varepsilon$ vs $\mathrm{T}$ data for heating and cooling processes, respectively. Circles are calculated from $\Delta \mathrm{T}_{\mathrm{S}} \mathrm{vs} \mathrm{T}$ data. The solid lines represent the linear fit for each curve. 
The entropy change was indirectly obtained by taking the derivative $(\mathrm{d} \varepsilon / \mathrm{dT})_{\sigma}$ from strain vs. T curves (See Fig. 2 and Fig. 3 in Supplemental Material [28]) and using Maxwell's relation to reach the following expression $[39,40]$ :

$$
\Delta S_{T}(T, \Delta \sigma)=-\frac{1}{\rho_{0}} \int_{\sigma_{1}}^{\sigma_{2}}\left(\frac{\partial \varepsilon}{\partial T}\right)_{\sigma} d \sigma
$$

where $\sigma$ and $\rho_{0}$ are the compressive stress and the density of the sample at atmospheric pressure and room temperature, respectively. $\varepsilon$ is the strain, defined as $\varepsilon \equiv \Delta l / l_{0}$, where $\Delta l$ is the length change of the sample and $l_{0}$ is the initial length, a constant measured at ambient pressure and room temperature.

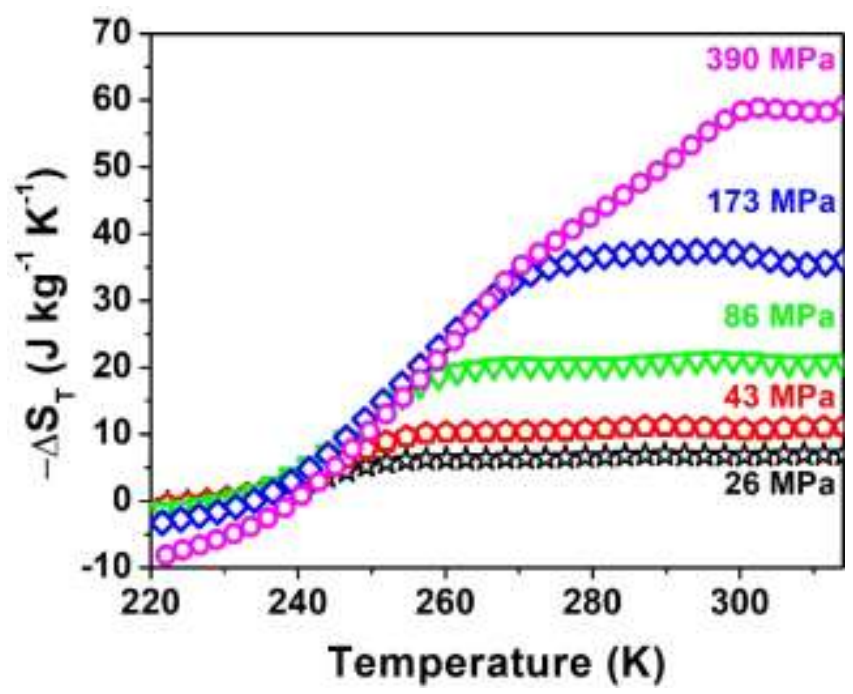

FIG. 3. Isothermal entropy change $\left(\Delta \mathrm{S}_{\mathrm{T}}\right)$ vs temperature on heating process for NBR. Values for $\Delta \sigma=$ 26.0(5), 43(1), 86(2), 173(3) and 390(12) MPa, obtained from $\varepsilon$ vs T data at isobaric process (Fig. 2 and Fig. 3 in Supplemental Material [28]).

We have obtained giant values of $\Delta \mathrm{S}_{\mathrm{T}}$ for the heating process, as shown in Fig. 3. At $314 \mathrm{~K}$ and $\Delta \sigma=390 \mathrm{MPa}$, a maximum $\Delta \mathrm{S}_{\mathrm{T}}$ of $59(6) \mathrm{J} \mathrm{kg}^{-1} \mathrm{~K}^{-1}$ was found. This leads to a normalized entropy change $\left(\left|\Delta \mathrm{S}_{\mathrm{T}} / \Delta \sigma\right|\right)$ of $0.15(2) \mathrm{kJ} \mathrm{kg}^{-1} \mathrm{~K}^{-1} \mathrm{GPa}^{-1}$. A clear influence of $\mathrm{T}_{\mathrm{g}}$ is also observed in the profile of $\Delta \mathrm{S}_{\mathrm{T}}$ vs. $\mathrm{T}$ curve in Fig. 3: the plateau indicates the rubbery state, while the steep region is due to the glassy state.

At low temperatures $(\mathrm{T} \leq 240 \mathrm{~K})$ we observe positive $\Delta \mathrm{S}_{\mathrm{T}}$ values, trend associated with the inverse thermal expansion observed in the $\varepsilon$ vs. T data on heating (see Fig. 2 in Supplemental Material [28]), which is pronounced for the higher pressures. This inverse entropy change is probably related to the molecular rearrangements taking place in, since the movement of polymer chains slows down drastically in the glassy state. Therefore, the system requires a longer time-scale to reach the thermodynamic equilibrium when compared with the rubbery state [34]. As consequence of this mechanism, we suppose the structure is retained while the temperature cools down in such a way that, on heating, the structure is relaxed and contracts (inverse thermal expansion). 
Envisaging the application of NBR in solid-state cooling, it is interesting to assess its performance under cyclic conditions. As we can see in $\varepsilon$ vs. $T$ data (see Fig. 4 in Supplemental Material [28]), NBR presents thermal hysteresis under cooling/heating cycles. Thermal hysteresis may be a drawback when considering the efficiency of refrigeration devices [41]. According to previous works [23,41], we calculated the reversible entropy changes $\left(\Delta \mathrm{S}_{\text {rev }}\right)$, defined as the intersection of the heating and cooling curves. This is represented by the shaded region in Fig. 4.

$\Delta \mathrm{S}_{\mathrm{rev}}$ fills a wide temperature range and slightly narrows as the pressure increases. Taking the $86 \mathrm{MPa}$ curve [Fig. 4(a)], the temperature range goes from $\sim 230 \mathrm{~K}$ to $314 \mathrm{~K}$ (range of $84 \mathrm{~K}$ ). On the other hand, for $390 \mathrm{MPa}$ [Fig. 4(c)], $\Delta \mathrm{S}_{\mathrm{rev}}$ was observed between 241 $\mathrm{K}$ and $314 \mathrm{~K}$ (range of $73 \mathrm{~K}$ ), only $13 \%$ smaller than that for $86 \mathrm{MPa}$. Moreover, the losses in $\Delta \mathrm{S}_{\mathrm{T}}$ values in the reversible range are minimum due to the hysteresis and are mostly located at the left borders of the shaded region, especially considering the lower pressure variations (87 and $173 \mathrm{MPa})$. For the highest pressure change, (390 MPa), $\Delta \mathrm{S}_{\text {rev }}$ is reduced by $15 \%$ (compared to the maximum $\Delta \mathrm{S}_{\mathrm{T}}$ in cooling process), but still maintaining its giant value of 56 $\mathrm{J} \mathrm{kg}^{-1} \mathrm{~K}^{-1}$ [Fig. 4(c)].

Another interesting aspect of $\Delta \mathrm{S}_{\text {rev }}$ region is its direct dependency on pressure. A good way to tackle this aspect is calculating the reversible refrigerant capacity $\left(\mathrm{RC}_{\text {rev }}\right)$ for several applied pressures. We can calculate $\mathrm{RC}_{\text {rev }}$ by integrating $\Delta \mathrm{S}_{\mathrm{rev}}$ over the reversible temperature range. In Fig. 5(a), we observe a linear increment of $\mathrm{RC}_{\text {rev }}$ values, which start to saturate at $234 \mathrm{MPa}$. The maximum $\mathrm{RC}_{\mathrm{rev}}$ of $2.7 \mathrm{~kJ} \mathrm{~kg}^{-1}$ is achieved at $390 \mathrm{MPa}$, although at $234 \mathrm{MPa}$ we already have a close value of $2.5 \mathrm{~kJ} \mathrm{~kg}^{-1}$. 

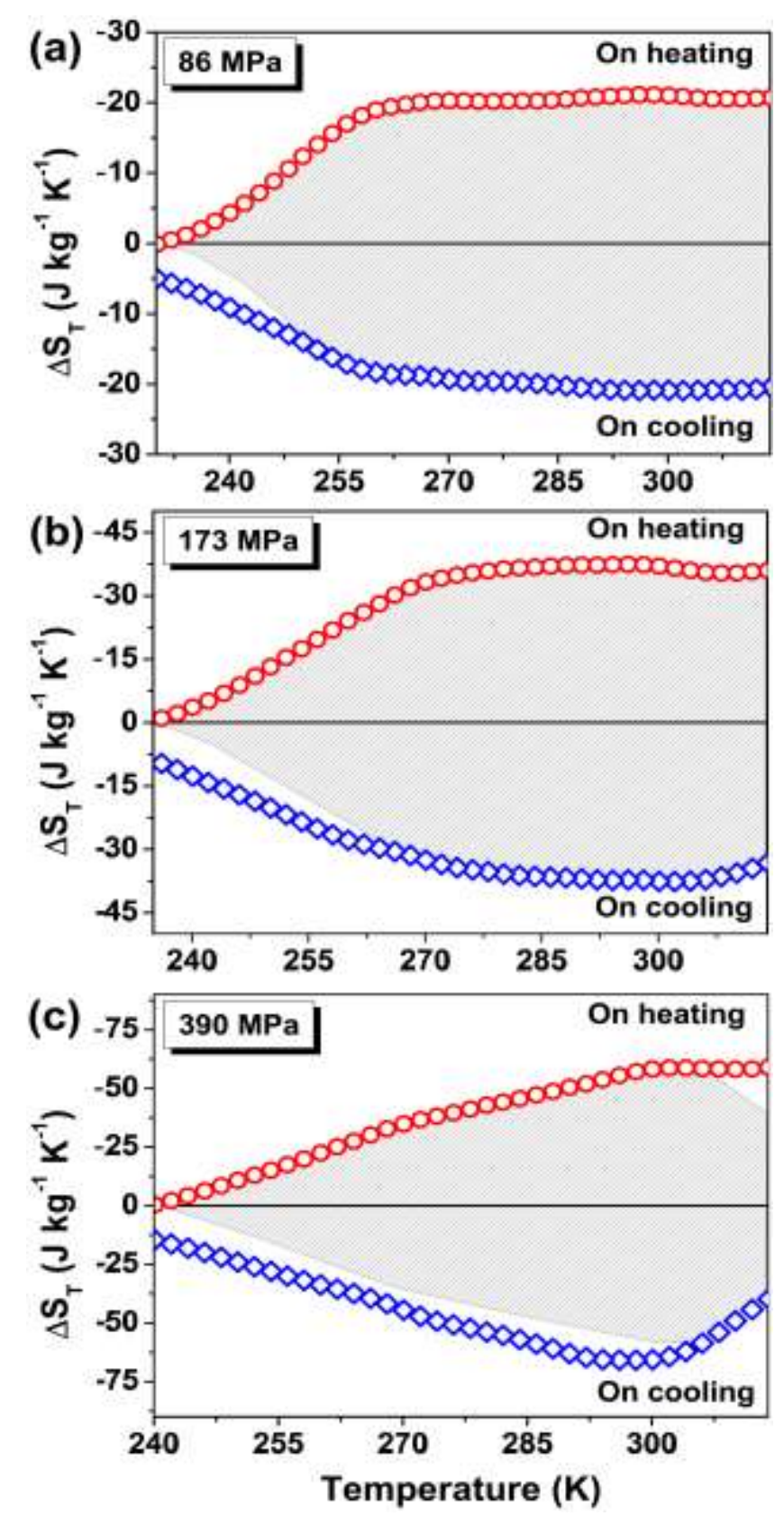

FIG. 4. Reversible entropy change for NBR. The red and blue curves are values for $\Delta \mathrm{S}_{\mathrm{T}}$ on heating and cooling processes, respectively. The shaded region corresponds to the reversible entropy change $\Delta S_{\text {rev. }}$.

Curves for pressures of 86 (a), 173 (b) and $390 \mathrm{MPa}$ (c) are shown.

To compare the barocaloric performance of different materials, the normalized refrigerant capacity $(\mathrm{NRC})$ is a useful parameter, which has been used before $[3,4]$ :

$$
N R C\left(\Delta T_{h-c}, \Delta \sigma\right)=\left|\frac{1}{\Delta \sigma} \int_{T_{\text {cold }}}^{T_{\text {hot }}} \Delta S_{T}(T, \Delta \sigma) d T\right|
$$

where $\Delta \mathrm{T}_{\mathrm{h}-\mathrm{c}} \equiv \mathrm{T}_{\text {hot }}-\mathrm{T}_{\text {cold }}$ is the temperature difference between the hot $\left(\mathrm{T}_{\text {hot }}\right)$ and cold $\left(\mathrm{T}_{\text {cold }}\right)$ reservoirs, $\Delta \sigma$ is the pressure change. NRC as function of $\Delta \mathrm{T}_{\mathrm{h}-\mathrm{c}}$ is shown in Fig. 5(b). For NBR, $T_{\text {hot }}$ was fixed at $315 \mathrm{~K}$ and $\mathrm{T}_{\text {cold }}$ was varied between $310 \mathrm{~K}$ and $240 \mathrm{~K}$ for $\Delta \sigma=173$ 
MPa. NRC values for NBR on the cooling process are similar to those obtained for heating process up to $\Delta \mathrm{T}_{\mathrm{h}-\mathrm{c}}=55 \mathrm{~K}$. Above that point, the cooling process results in slightly higher values of NRC. Nevertheless, both heating and cooling present huge values of NRC, with a clear trend to increase.

When comparing NRC results of NBR with other materials, it is significantly higher than intermetallics $\mathrm{Mn}_{3} \mathrm{GaN}$ [42] and $\mathrm{Fe}_{49} \mathrm{Rh}_{51}$ [23], which both presenting a curve profile that tend to saturate at $\Delta \mathrm{T}_{\mathrm{h}-\mathrm{c}}=15 \mathrm{~K}$. Comparing with PDMS, the values for NBR are higher for $\Delta \mathrm{T}_{\text {h-c }}$ up to $20 \mathrm{~K}$. Lastly, NBR presents lower NRC values when comparing with V-NR due to the higher $\Delta \mathrm{S}_{\mathrm{T}}$ values of the later material in the compared range. But for $\Delta \mathrm{T}_{\mathrm{h}-\mathrm{c}}$ up to $10 \mathrm{~K}$, both materials have similar values of NRC.
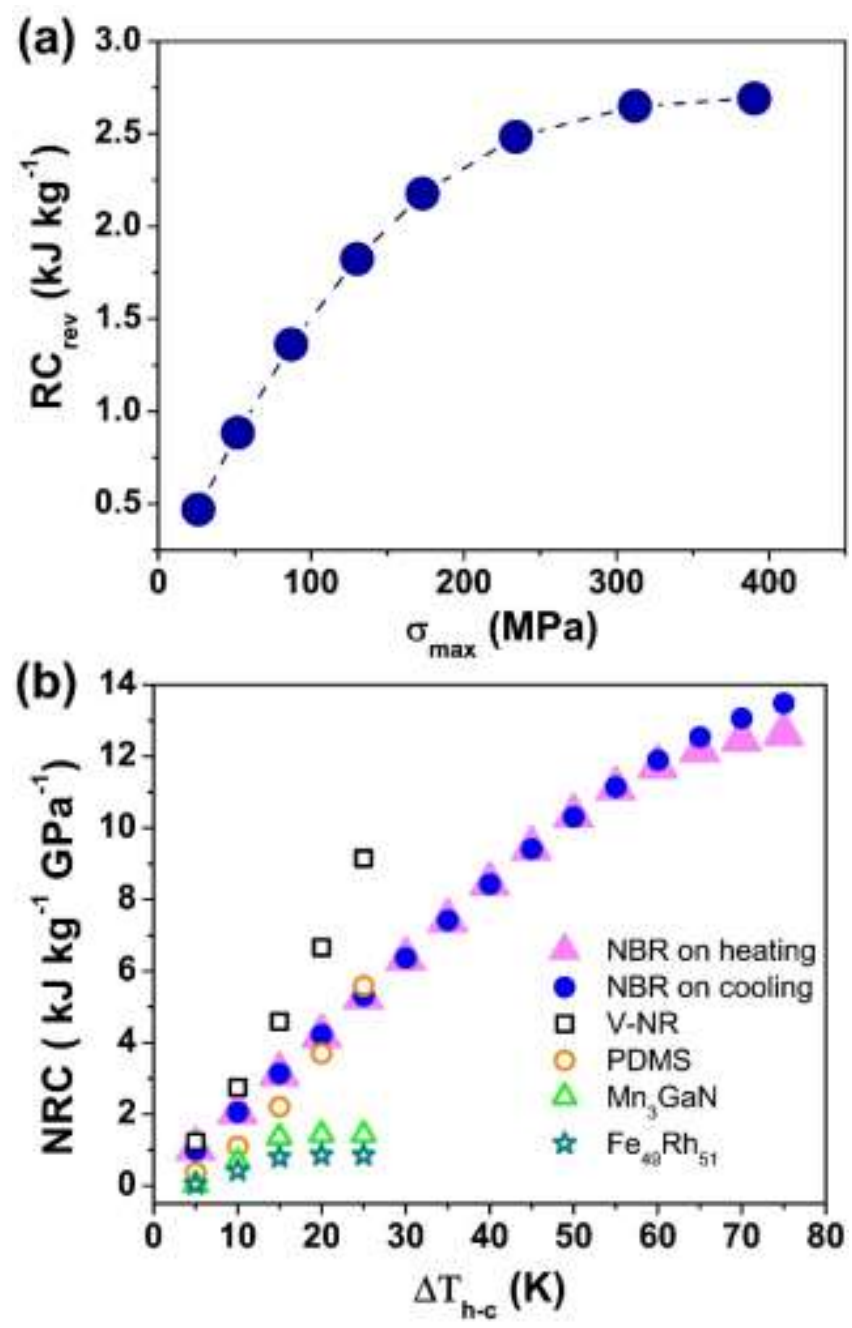

FIG. 5. (a) Reversible refrigerant capacity as a function of applied pressure. (b) Normalized refrigerant capacity as a function of $\Delta \mathrm{T}_{\mathrm{h}-\mathrm{c}}=\mathrm{T}_{\text {hot }}-\mathrm{T}_{\text {cold }}$ (temperature difference between hot and cold reservoirs): NBR (both heating and cooling processes are shown; $\mathrm{T}_{\text {hot }}=315 \mathrm{~K},|\Delta \sigma|=173 \mathrm{MPa}$ ); V-NR ( $\mathrm{T}_{\text {hot }}=$ $315 \mathrm{~K},|\Delta \sigma|=130 \mathrm{MPa}$ ); PDMS ( $\mathrm{T}_{\text {hot }}=315 \mathrm{~K},|\Delta \sigma|=130 \mathrm{MPa}$ ) [3]; $\mathrm{Mn}_{3} \mathrm{GaN}\left(\mathrm{T}_{\text {hot }}=295 \mathrm{~K},|\Delta \sigma|=\right.$ $139 \mathrm{MPa})$ [42]; $\mathrm{Fe}_{49} \mathrm{Rh}_{51}\left(\mathrm{~T}_{\text {hot }}=325 \mathrm{~K},|\Delta \sigma|=160 \mathrm{MPa}\right)$ [23].

\section{CONCLUSION}

Our results on $\sigma_{b}$-CE of NBR demonstrate its promising potential regarding applications in solid-state cooling. Giant $\Delta \mathrm{T}_{\mathrm{S}}$ values of $16.4(2) \mathrm{K}$ (at $323 \mathrm{~K}$ ) and $\Delta \mathrm{S}_{\mathrm{T}}$ of $59(6)$ 
$\mathrm{J} \mathrm{kg}^{-1} \mathrm{~K}^{-1}$ (at $314 \mathrm{~K}$ ) were obtained at relatively moderate applied pressures (390 MPa) and around room temperature. These results lead to huge normalized values: $0.15(2) \mathrm{J} \mathrm{kg}^{-1} \mathrm{~K}^{-1} \mathrm{GPa}^{-}$ ${ }^{1}$ for $\left|\Delta \mathrm{S}_{\mathrm{T}} / \Delta \sigma\right|$ and $42(2) \mathrm{K} \mathrm{GPa}^{-1}$ for $\left|\Delta \mathrm{T}_{\mathrm{S}} / \Delta \sigma\right|$, comparable to the best barocaloric materials in the literature. Besides, $\Delta \mathrm{T}_{\mathrm{S}}$ demonstrated to be rather reversible: the compression and decompression results are very similar. Despite the hysteretic behavior of the material, reversible entropy change extends to a wide temperature range with minimal losses, keeping its giant values. NBR glass transition strongly influences $\sigma_{b}$-CE results, explaining the decreasing behavior of $\Delta \mathrm{T}_{\mathrm{S}}$ and $\Delta \mathrm{S}_{\mathrm{T}}$ values as the pressure change increases and temperature is reduced. Moreover, we determined the pressure coefficient of the glass transition in three distinct processes: isobaric strain vs. temperature curves on heating and on cooling processes, and from $\Delta \mathrm{T}_{\mathrm{S}}$ data.

\section{ACKNOWLEDGMENT}

The authors acknowledge financial support from FAPESP (project number 2016/22934-3), CNPq, CAPES, LNLS and CNPEM.

\section{REFERENCES}

[1] F. Edition, The Science and Technology of Rubber (2013).

[2] E. O. Usuda, N. M. Bom, and A. M. G. Carvalho, Eur. Polym. J. 92, 287 (2017).

[3] N. M. Bom, W. Imamura, E. O. Usuda, L. S. Paixao, and A. M. G. Carvalho, ACS Macro Lett. 7, 31 (2018).

[4] A. M. G. Carvalho, W. Imamura, E. O. Usuda, and N. M. Bom, Eur. Polym. J. 99, 212 (2018).

[5] W. Imamura, E. O. Usuda, L. S. Paixão, N. M. Bom, and A. M. G. Carvalho, arXiv:1710.01761 (2017).

[6] S. Crossley, N. D. Mathur, and X. Moya, AIP Adv. 5, 067153 (2015).

[7] L. Mañosa, A. Planes, and M. Acet, J. Mater. Chem. A 1, 4925 (2013).

[8] I. Takeuchi and K. Sandeman, Phys. Today 68, 48 (2015).

[9] V. K. Pecharsky and K. A. Gschneidner, Jr., Phys. Rev. Lett. 78, 4494 (1997).

[10] A. S. Mischenko, Q. Zhang, J. F. Scott, R. W. Whatmore, and N. D. Mathur, Science 311, 1270 (2006).

[11] L. Mañosa, D. González-alonso, A. Planes, E. Bonnot, M. Barrio, J. Tamarit, S. Aksoy, and M. Acet, Nat. Mater. 9, 478 (2010).

[12] J. Gough, Memories Lit. Philos. Soc. Manchester 1, 288 (1805).

[13] W. Thomson, Q. J. Math. 1, 57 (1855).

[14] W. Thomson, Philos. Mag. Ser. 5, 4 (1878).

[15] R. R. Wu, L. F. Bao, F. X. Hu, H. Wu, Q. Z. Huang, J. Wang, X. L. Dong, G. N. Li, J. R. Sun, F. R. Shen, T. Y. Zhao, X. Q. Zheng, L. C. Wang, Y. Liu, W. L. Zuo, Y. Y. Zhao, M. Zhang, X. C. Wang, C. Q. Jin, G. H. Rao, X. F. Han, and B. G. Shen, Sci. Rep. 5, 1 (2015).

[16] M. Gorev, E. Bogdanov, I. Flerov, and N. Laptash, J. Phys. Condens. Matter 22, 185901 (2010).

[17] M. V Gorev, E. V Bogdanov, I. N. Flerov, A. G. Kocharova, and N. M. Laptash, Phys. Solid State 52, 167 (2010).

[18] M. V. Gorev, I. N. Flerov, E. V. Bogdanov, V. N. Voronov, and N. M. Laptash, Phys. Solid State 52, 377 (2010). 
[19] I. N. Flerov, A. V. Kartashev, M. V. Gorev, E. V. Bogdanov, S. V. Mel'Nikova, M. S. Molokeev, E. I. Pogoreltsev, and N. M. Laptash, J. Fluor. Chem. 183, 1 (2016).

[20] C. Cazorla and D. Errandonea, Nano Lett. 16, 3124 (2016).

[21] L. Mañosa, D. González-Alonso, A. Planes, M. Barrio, J. L. Tamarit, I. S. Titov, M. Acet, A. Bhattacharyya, and S. Majumdar, Nat. Commun. 2, 1 (2011).

[22] S. Yuce, M. Barrio, B. Emre, E. Stern-Taulats, A. Planes, J. L. Tamarit, Y. Mudryk, K. A. Gschneidner, V. K. Pecharsky, and L. Mañosa, Appl. Phys. Lett. 101, 071906 (2012).

[23] E. Stern-Taulats, A. Planes, P. Lloveras, M. Barrio, J. L. Tamarit, S. Pramanick, S. Majumdar, C. Frontera, and L. Mañosa, Phys. Rev. B 89, 214105 (2014).

[24] P. Lloveras, E. Stern-Taulats, M. Barrio, J. L. Tamarit, S. Crossley, W. Li, V. Pomjakushin, A. Planes, L. Mañosa, N. D. Mathur, and X. Moya, Nat. Commun. 6, 8801 (2015).

[25] E. Stern-Taulats, P. Lloveras, M. Barrio, E. Defay, M. Egilmez, A. Planes, J. L. Tamarit, L. Mañosa, N. D. Mathur, and X. Moya, APL Mater. 4, 091102 (2016).

[26] J. M. Bermúdez-García, M. Sánchez-Andújar, S. Castro-García, J. López-Beceiro, R. Artiaga, and M. A. Señarís-Rodríguez, Nat. Commun. 8, 15715 (2017).

[27] E. L. Rodriquez and F. E. Filisko, J. Appl. Phys. 53, 6536 (1982).

[28] See Supplemental Material at [URL] for FT-IR and Strain-Temperature data for NBR sample

[29] N. M. Bom, E. O. Usuda, G. M. Guimarães, A. A. Coelho, and A. M. G. Carvalho, Rev. Sci. Instrum. 88, 046103 (2017).

[30] L. Mañosa and A. Planes, Adv. Mater. 29, 1603607 (2017).

[31] J. E. McKinney and M. Goldstein, J. Res. Natl. Bur. Stand. Sect. A Phys. Chem. 78A, 331 (1974).

[32] J. J. Tribone, J. M. O'reilly, and J. Greener, J. Polym. Sci. Part B Polym. Phys. 27, 837 (1989).

[33] H. A. Schneider, J. Therm. Anal. 47, 453 (1996).

[34] J. M. Hutchinson, Prog. Polym. Sci. 20, 703 (1995).

[35] T. S. Chow, Mesoscopic Physics of Complex Materials (Springer New York, New York, NY, 2000).

[36] C. A. Angell and W. Sichina, Ann. N. Y. Acad. Sci. 279, 53 (1976).

[37] J. E. K. Schawe, Thermochim. Acta 603, 128 (2015).

[38] T. V Tropin, J. W. Schmelzer, and V. L. Aksenov, Physics-Uspekhi 59, 42 (2016).

[39] M. M. Vopson, J. Phys. D. Appl. Phys. 46, 345304 (2013).

[40] Y. Liu, I. C. Infante, X. Lou, L. Bellaiche, J. F. Scott, and B. Dkhil, Adv. Mater. 26, $6132(2014)$.

[41] O. Gutfleisch, T. Gottschall, M. Fries, D. Benke, I. Radulov, K. P. Skokov, H. Wende, M. Gruner, M. Acet, P. Entel, and M. Farle, Philos. Trans. R. Soc. A Math. Phys. Eng. Sci. 374, 20150308 (2016).

[42] D. Matsunami, A. Fujita, K. Takenaka, and M. Kano, Nat. Mater. 14, 73 (2015). 


\section{Supplemental Material: \\ FT-IR and Strain-Temperature data for NBR sample}

E. O. Usuda, ${ }^{1,2}$ W. Imamura, ${ }^{1,3}$ N. M. Bom, ${ }^{1}$ L. S. Paixão, ${ }^{1}$ A. M. G. Carvalho, ${ }^{1}$

${ }^{1}$ Laboratório Nacional de Luz Síncrotron (LNLS), Centro Nacional de Pesquisa em Energia e Materiais (CNPEM),CEP 13083-100, Campinas, SP, Brazil

${ }^{2}$ Departamento de Ciências Exatas e da Terra, Universidade Federal de São Paulo (UNIFESP), CEP 00972270, Diadema, SP, Brazil.

${ }^{3}$ Faculdade de Engenharia Mecânica, Universidade Estadual de Campinas (UNICAMP), CEP 13083-860, Campinas, SP, Brazil.

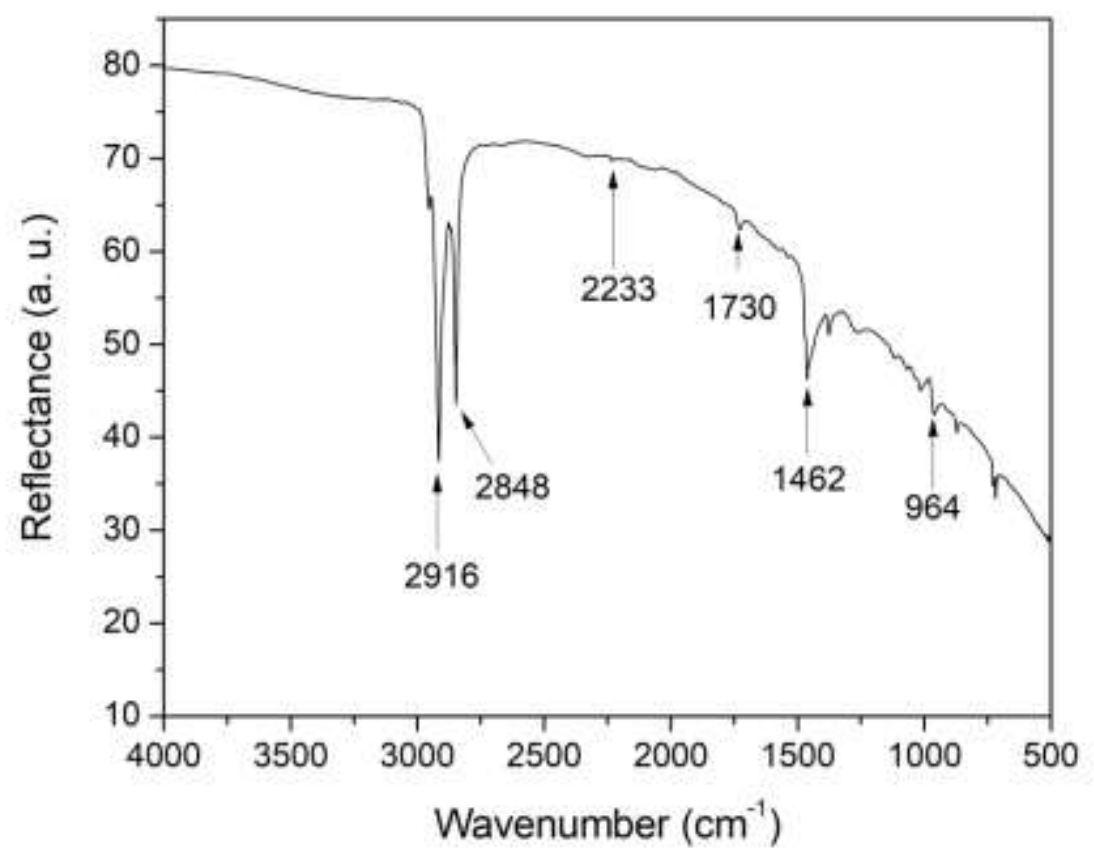

FIG. 1. FT-IR spectrum of NBR filled with carbon black. The bands are in accordance with the literature $[1,2]$. 


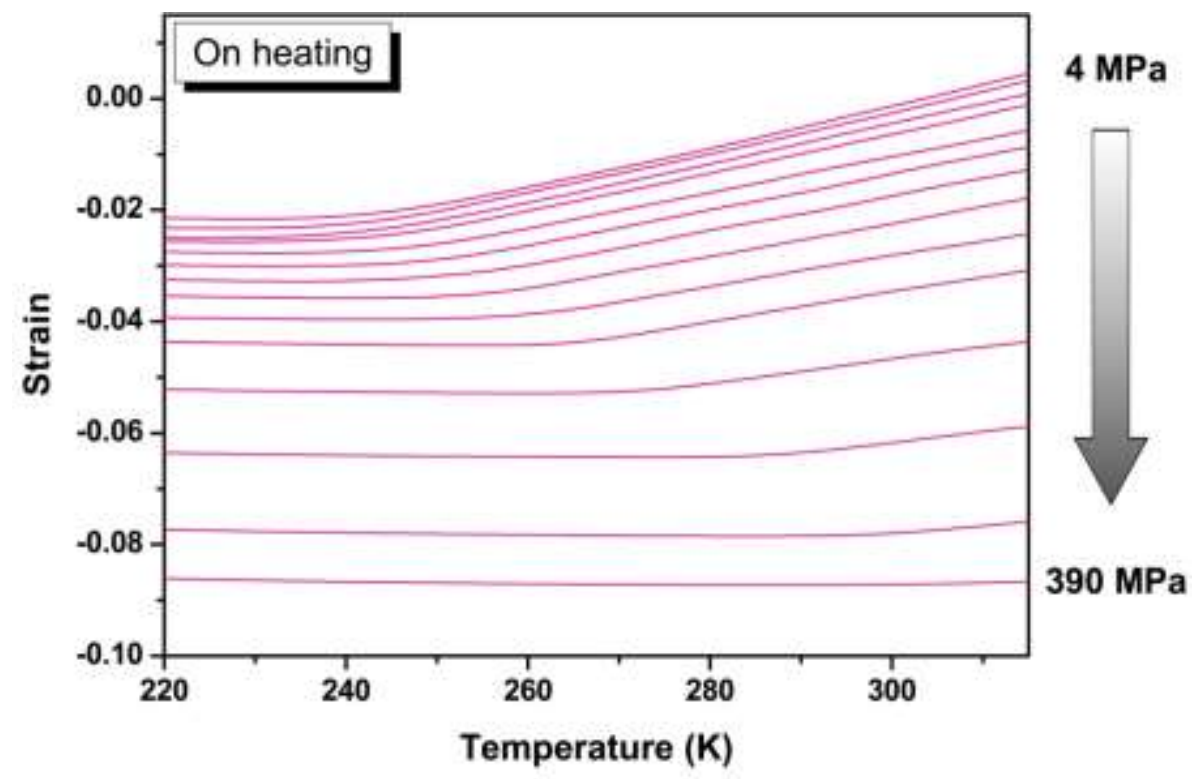

FIG. 2. Strain as a function of temperature for NBR on heating processes for various pressures (4 MPa $-390 \mathrm{MPa})$.

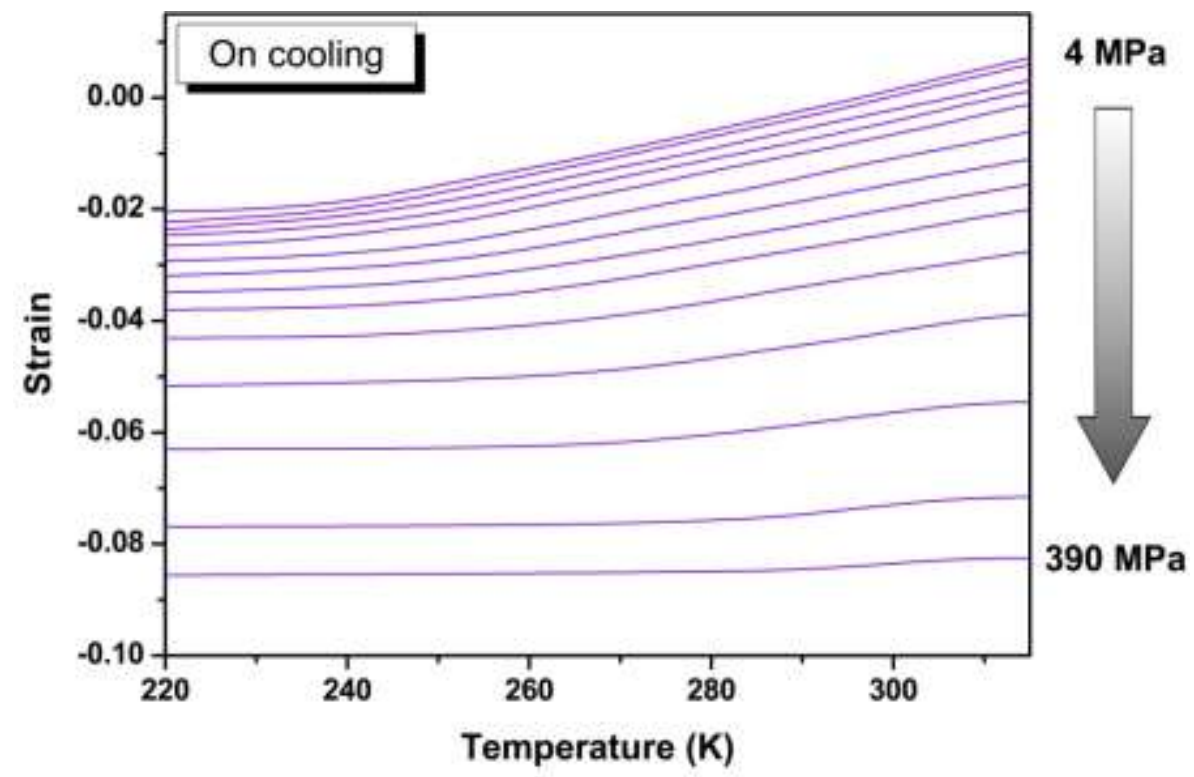

FIG. 3. Strain as a function of temperature for NBR on cooling processes for various pressures (4 MPa $-390 \mathrm{MPa})$. 


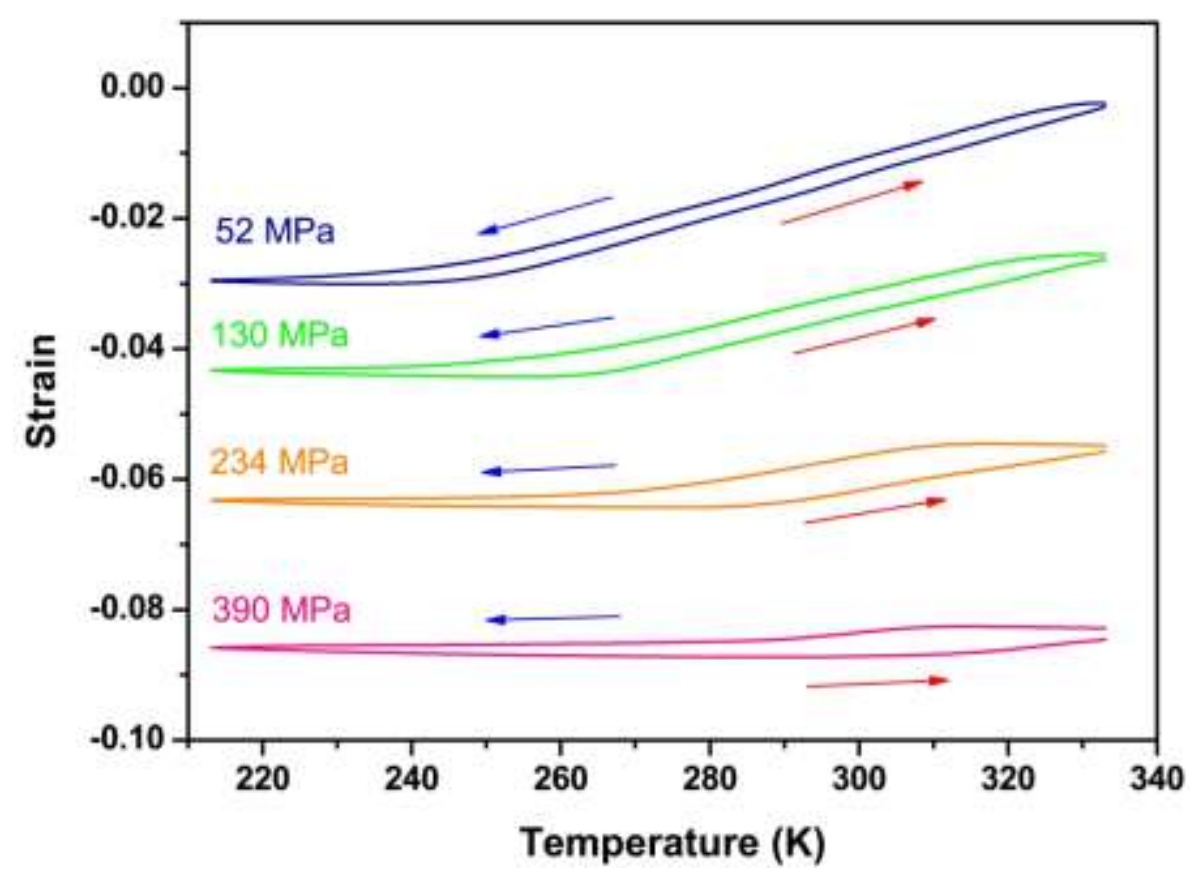

FIG. 4. Complete cycles of strain vs. temperature measurements for pressures of 52, 130, 234 and 390 MPa.

\section{REFERENCES}

[1] X. Liu, J. Zhao, R. Yang, R. Iervolino, and S. Barbera, Polym. Degrad. Stab. 151, 136 (2018).

[2] J. Liu, X. Li, L. Xu, and P. Zhang, Polym. Test. 54, 59 (2016). 